\title{
STUDI KUALITAS PELAYANAN LISTRIK TERHADAP KEPUASAN PELANGGAN PT PLN (PERSERO) RAYON TABANAN
}

\author{
I Putu Supardiasa ${ }^{1}$, AA Gede Maharta Pemayun ${ }^{2}$, I Wayan Rinas ${ }^{3}$ \\ Jurusan Teknik Elektro dan Komputer, Fakultas Teknik, Universitas Udayana \\ Email: iputusupardiasa@ymail.com ${ }^{1}$, maharta@unud.ac.id², rinas@unud,ac.id ${ }^{3}$
}

\begin{abstract}
ABSTRAK
Tingkat kepuasan terhadap pelayanan yang diberikan oleh PLN menjadi prioritas utama yang wajib didapatkan oleh pelanggan. Tujuan yan ingin dicapai dari penelitian ini adalah untuk mengetahui kualitas pelayanan listrik terhadap kepuasan pelanggan PT PLN (Persero) Rayon Tabanan. Dalam penelitian ini menggunakan 100 responden dengan menggunakan metode non random sampling dalam pemilihan sampel. Penelitian menggunakan olah data statistik dan observasi. Olah data statistik adalah hasil dari penilaian responden pada importance performance analysis, uji validitas dan diagram kartesius. Observasi adalah pengamatan langsung dalam penelitian. Hasil Penelitian ini menunjukkan bahwa pelanggan listrik Rayon Tabanan merasa puas terhadap kualitas pelayanan listrik PT PLN (Persero) Rayon Tabanan karena penilaian responden pada kontinuitas listrik di tingkat yang dirasakan sudah sesuai dengan yang diharapkan pelanggan dengan perhitungan SPSS sebesar 4,59\% dan untuk nilai yang terendah $3,49 \%$ yaitu kecepatan pelayanan permohonan PB/PD/PS.
\end{abstract}

Kata Kunci : Kepuasan, pelanggan, SPSS

\begin{abstract}
The level of satisfaction with the service provided by PLN becomes the main priority that must be obtained by the customers. The purpose of this research is to know the quality of electricity service to customer satisfaction PT PLN (Persero) Rayon Tabanan. In this research using 100 respondents by using non random sampling method in sample selection. There are two methods used in the research is the method of statistical data and methods of observation. Statistical data is the result of respondents' assessment on importance performance analysis, validity test and Cartesian diagram. Observation is a direct observation in the study. The results of this study indicate that electricity customers Rayon Tabanan feel satisfied with the quality of electricity service PT PLN (Persero) Rayon Tabanan because the assessment of respondents on electrical continuity in the level that is felt in accordance with the expected customers with SPSS calculation of $4.59 \%$ and for the value the lowest of $3.49 \%$ is the speed of PB / PD / PS application.
\end{abstract}

Keywords : Satisfaction, customer, SPSS

\section{PENDAHULUAN}

Energi listrik adalah kebutuhan pokok dalam kehidupan manusia saat ini. Perusahaan seperti PLN berlomba - lomba menghasilkan layanan dan produk untuk memenuhi keinginan dan kebutuhan pelanggan agar pelanggan merasa puas dengan yang telah didapatkan dari perusahaan [1].
Penelitian ini bertujuan untuk mengetahui kualitas pelayanan PT PLN (Persero) Rayon Tabanan terhadap kepuasan pelanggan. Obyek penelitian ini bergerak pada sektor rumah tangga, karena setiap tahunnya pelanggan cenderung mengalami peningkatan. Pengukuran menggunakan skala likert dan penyelesaiannya menggunakan software SPSS. 


\section{KAJIAN PUSTAKA}

\subsection{Kepuasan Pelanggan}

Yang dimaksud kepuasan pelanggan adalah timbulnya perasaan kecewa atau senang seseorang dalam membandingkan hasil yang dipikirkan terhadap yang diharapkan. Tujuan dari bisnis untuk menciptakan pelanggan merasa puas.

\subsection{Mengolah Data Statistik}

A. Uji Validitas

Menentukan valid dalam kuisioner [3].

Untuk mengujinya dilakukan dengan rumus berikut [4]

$$
r x y=\frac{n \sum X Y-\left(\sum x\right)\left(\sum Y\right)}{\sqrt{\left(n \sum x^{2}-\left(N \sum Y\right)^{2}+N \sum Y^{2}-\left(\sum Y\right)^{2}\right)}}
$$

Keterangan :

$r x y=$ Koefisien korelasi dengan jumlah item dan jumlah total

$X=$ Jumlah item

$Y=$ Jumlah total

$\mathrm{N}=$ Populasi

$\mathrm{n}=$ Jumlah sampel

B. Importance Performance Analysis Menghasilkan kuadran yang berbeda pada bentuk diagram kartesius [5].

$$
\overline{\mathrm{X}}=\sum \frac{\mathrm{Xi}}{\mathrm{n}}
$$

Keterangan :

$\overline{\mathrm{X}}=$ nilai kinerja rata - rata pada $\mathrm{i}$

$\mathrm{Xi}=$ Hasil seluruh kinerja pada pelanggan

$\mathrm{n}$ = Hasil sampel

$$
\overline{Y_{\tau}}=\Sigma \frac{\mathrm{Yi}}{\mathrm{n}}
$$

Keterangan :

$\overline{Y_{l}}=$ nilai kinerja rata - rata pada $\mathrm{i}$

$Y i=$ Hasil seluruh kepentingan pada pelanggan

$\mathrm{n}=$ Hasil sampel

$$
\mathrm{X}=\Sigma \frac{\overline{X I}}{\mathrm{~K}}
$$

Keterangan :

$\mathrm{X}=$ Jumlah nilai kinerja rata - rata pada $\mathrm{i}$

$\overline{\bar{Z}}=$ Hasil seluruh kinerja pada pelanggan
$\mathrm{K}=$ Hasil variabel yang dipakai

$$
\mathrm{Y}=\sum \frac{\mathrm{YI}}{\mathrm{K}}
$$

Keterangan :

$\mathrm{Y}=$ Jumlah nilai kepentingan rata - rata pada $\mathrm{i}$

$\overline{Y_{\imath}}=$ Hasil seluruh kepentingan pada pelanggan

$\mathrm{K}=$ Hasil variabel yang dipakai

Ditunjukkan pada gambar 1 importance $(X)$ dan performance $(\mathrm{Y})$ berikut [6] :

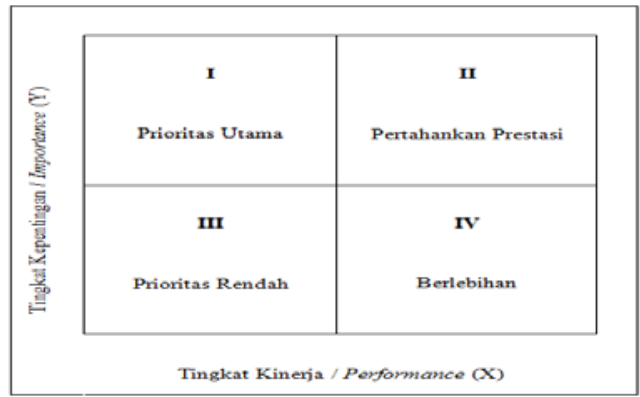

Gambar 1. Diagram Kartesius Importance Performance Analysis

a.(I) Meliputi tempat yang utama agar di perbaiki.

b. (II) Sebagai kuadran yang bagus untuk dipertahankan.

c. (III)

Sebagai daerah prioritas rendah.

d. (IV)

Sebagai daerah berlebihan.

\section{METODE PENELITIAN}

Penelitian dimulai dari bulan Juli 2016 sampai September 2016 dengan mengadakan survey kepada pelanggan Rayon Tabanan menggunakan software SPSS.

Perhitungan yang pertama yaitu mencari data jumlah pelanggan yang akan dijadikan populasi, menghitung jumlah sampel dari populasi. Penentuan sampel dengan teknik non random sampling. Analisis kuisioner dengan skala likert, uji validitas, analysis importance performance dan pengurutan nilai setiap item pertanyaan. 
Bahwa jumlah pria lebih banyak dibandingkan wanita sebesar $88 \%$.

B. Jenis Umur

Tabel 2. Pelanggan Berdasarkan Jenis Umur

\subsection{Alur Analis Data}

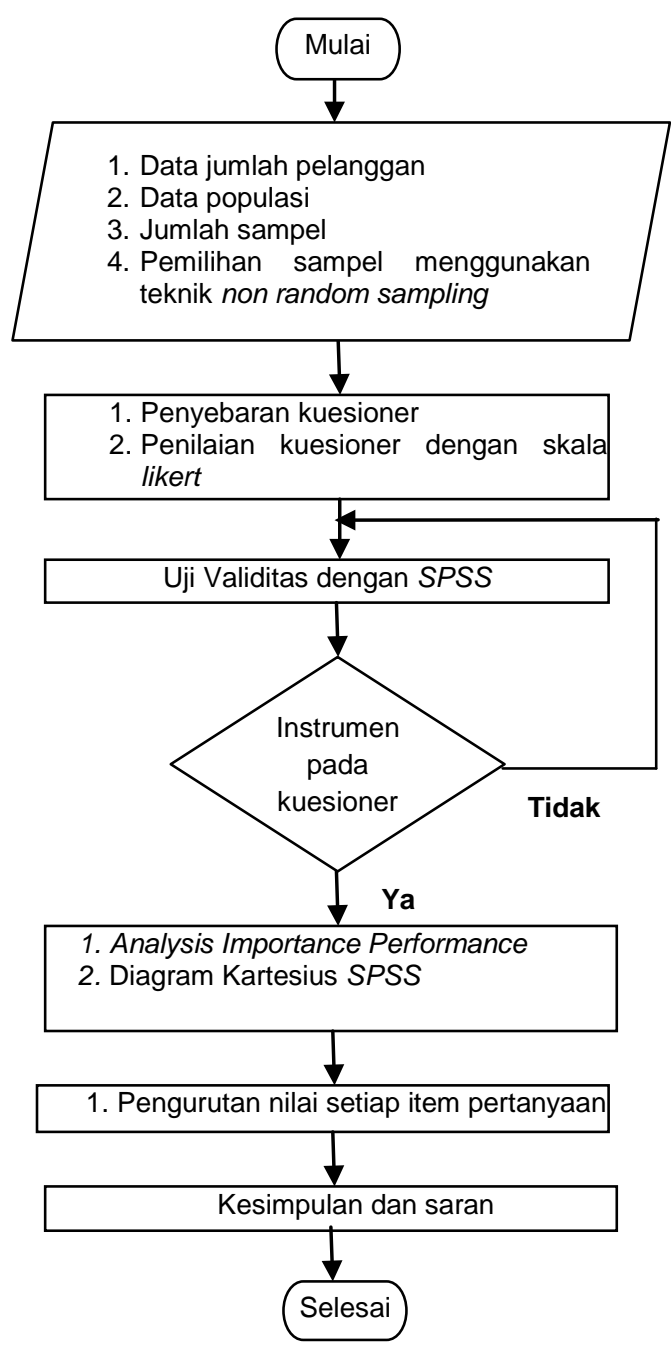

4. HASIL DAN PEMBAHASAN

4.1 Gambaran Umum Pelanggan

Penyebaran kuisioner sebanyak 100 pelanggan

\section{A. Jenis kelamin}

Tabel 1. Pelanggan Berdasarkan Jenis Kelamin

\begin{tabular}{|c|c|c|c|}
\hline No & Jenis Kelamin & Total & $\begin{array}{c}\text { Persentase } \\
(\%)\end{array}$ \\
\hline 1 & Pria & 88 & $88 \%$ \\
\hline 2 & Wanita & 12 & $12 \%$ \\
\hline & Total & 100 & $100 \%$ \\
\hline
\end{tabular}

\begin{tabular}{|c|c|c|c|}
\hline No & Umur & Total & $\begin{array}{c}\text { Persentase } \\
(\%)\end{array}$ \\
\hline 1 & $\leq 20$ tahun & 2 & $2 \%$ \\
\hline 2 & $21-30$ tahun & 18 & $18 \%$ \\
\hline 3 & $31-40$ tahun & 29 & $29 \%$ \\
\hline 4 & $41-50$ tahun & 30 & $30 \%$ \\
\hline 5 & $>51$ tahun & 21 & $21 \%$ \\
\hline \multicolumn{2}{|c|}{ Total } & 100 & $100 \%$ \\
\hline
\end{tabular}

Total umur yang terbesar adalah 30\% yaitu umur 41 sampai 50 tahun.

\subsection{Uji Validitas}

Tabel 3. Hasil Uji Validitas Pada SPSS

\begin{tabular}{|c|c|c|c|c|}
\hline No & $\begin{array}{c}\text { Item } \\
\text { Pertanyaan } \\
\text { Ke- }\end{array}$ & $r_{\text {hitung }}$ & $r_{\text {tabel }}$ & Keterangan \\
\hline 1 & 1 & 0,454 & 0,196 & save \\
\hline 2 & 2 & 0,764 & 0,196 & save \\
\hline 3 & 3 & 0,532 & 0,196 & save \\
\hline 4 & 4 & 0,451 & 0,196 & save \\
\hline 5 & 5 & 0,770 & 0,196 & save \\
\hline 6 & 6 & 0,546 & 0,196 & save \\
\hline 7 & 7 & 0,809 & 0,196 & save \\
\hline 8 & 8 & 0,816 & 0,196 & save \\
\hline 9 & 9 & 0,848 & 0,196 & save \\
\hline 10 & 10 & 0,446 & 0,196 & save \\
\hline 11 & 11 & 0,889 & 0,196 & save \\
\hline 12 & 12 & 0,784 & 0,196 & save \\
\hline
\end{tabular}

Dapat dilihat pada Tabel 3 save merupakan valid dari item pertanyaan bahwa nilai $r_{\text {hitung }}$ lebih besar dari nilai $r_{\text {tabel. }}$ Pada uji validitas, jika nilai $r_{\text {hitung }}$ lebih besar dari $r_{\text {tabel }}$ maka dikatakan valid.

\subsection{Importance Performance Analysis}

Dalam pembuatan diagram kartesius, yang pertama dicari adalah nilai rata - rata pada kuisioner. Kemudian menentukan skala likert pada setiap pertanyaan di kuisioner yaitu bernilai 5 (SM), 4 (M), 3 (CM), 2 (KM), 1 (TM). 
Tabel 3. Penilaian Pelanggan Pada Tingkat Yang Dirasakan

\begin{tabular}{|c|c|c|c|c|c|c|c|c|c|c|c|c|c|c|}
\hline \multirow[b]{2}{*}{ No. } & \multirow[b]{2}{*}{$\begin{array}{l}\text { Variabel Kualitas } \\
\text { Pelayanan }\end{array}$} & \multicolumn{5}{|c|}{ Tingkat Yang Dirasakan } & \multirow[b]{2}{*}{ Jml. } & \multicolumn{5}{|c|}{ Skor } & \multirow[b]{2}{*}{ Jml. } & \multirow{2}{*}{$\begin{array}{l}\text { Rat } \\
\text { a- } \\
\text { rata } \\
(\%)\end{array}$} \\
\hline & & SM & M & $\mathrm{CM}$ & $\begin{array}{l}\mathrm{K} \\
\mathrm{M}\end{array}$ & TM & & 5 & 4 & 3 & 2 & 1 & & \\
\hline \multicolumn{15}{|c|}{ Frekuensi Gangguan } \\
\hline 1 & $\begin{array}{l}\text { Kestabilan tegangan di } \\
\text { tempat anda }\end{array}$ & 29 & 60 & 11 & 0 & 0 & 100 & 145 & 240 & 33 & 0 & 0 & 418 & 4,18 \\
\hline 2 & $\begin{array}{c}\text { Kontinuitas listrik (tidak } \\
\text { pernah padam) }\end{array}$ & 66 & 27 & 7 & 0 & 0 & 100 & 330 & 108 & 21 & 0 & 0 & 459 & 4,59 \\
\hline 3 & $\begin{array}{l}\text { Lamanya padam dan } \\
\text { respon pemulihan }\end{array}$ & 31 & 41 & 16 & 9 & 3 & 100 & 155 & 164 & 48 & 18 & 3 & 388 & 3,88 \\
\hline \multicolumn{15}{|c|}{ Respon Pengaduan } \\
\hline 4 & $\begin{array}{l}\text { Kecepatan merespon } \\
\text { keluhan pelanggan } \\
\text { (kWh prabayar error, } \\
\text { muncul tulisan "periksa") }\end{array}$ & 29 & 32 & 29 & 7 & 3 & 100 & 145 & 128 & 87 & 14 & 3 & 377 & 3,77 \\
\hline 5 & $\begin{array}{c}\text { Kecepatan petugas } \\
\text { mengatasi keluhan } \\
\text { pelanggan }\end{array}$ & 29 & 31 & 29 & 9 & 2 & 100 & 145 & 124 & 87 & 18 & 2 & 376 & 3,76 \\
\hline 6 & $\begin{array}{l}\text { Keterbukaan informasi } \\
\text { perhitungan tagihan }\end{array}$ & 27 & 54 & 12 & 5 & 2 & 100 & 135 & 216 & 36 & 10 & 2 & 399 & 3,99 \\
\hline \multicolumn{15}{|c|}{ Pelayanan PB/PD/PS } \\
\hline 7 & $\begin{array}{c}\text { Kejelasan dan } \\
\text { kemudahan prosedur } \\
\text { PB/PD/PS }\end{array}$ & 37 & 29 & 29 & 4 & 1 & 100 & 185 & 116 & 87 & 8 & 1 & 397 & 3,97 \\
\hline 8 & $\begin{array}{c}\text { Kecepatan pelayanan } \\
\text { permohonan } \\
\text { PB/PD/PS } \\
\end{array}$ & 22 & 27 & 34 & 12 & 5 & 100 & 110 & 108 & $\begin{array}{c}10 \\
2\end{array}$ & 24 & 5 & 349 & 3,49 \\
\hline \multicolumn{15}{|c|}{ Layanan Lainnya } \\
\hline 9 & $\begin{array}{l}\text { Kemudahan memahami } \\
\text { informasi di Web, call } \\
\text { centre, media cetak }\end{array}$ & 38 & 36 & 15 & 7 & 4 & 100 & 190 & 144 & 45 & 14 & 4 & 397 & 3,97 \\
\hline 10 & $\begin{array}{c}\text { Kemudahan } \\
\text { menghubungi call centre } \\
\text { PLN } 123\end{array}$ & 25 & 50 & 15 & 6 & 4 & 100 & 125 & 200 & 45 & 12 & 4 & 386 & 3,86 \\
\hline 11 & $\begin{array}{l}\text { Layanan gratis bongkar } \\
\text { pasang kWh prabayar } \\
\text { jika mengalami error }\end{array}$ & 37 & 37 & 12 & 8 & 6 & 100 & 185 & 148 & 36 & 16 & 6 & 391 & 3,91 \\
\hline 12 & $\begin{array}{l}\text { Kemudahan dalam } \\
\text { membeli voucher listrik } \\
\text { prabayar }\end{array}$ & 31 & 52 & 12 & 5 & 0 & 100 & 155 & 208 & 36 & 10 & 0 & 409 & 4,09 \\
\hline
\end{tabular}

Dari Tabel 3 terlihat bahwa kuesioner pada tingkat yang dirasakan. Untuk mencari total nilai rata-rata menggunakan persamaan 4 berikut :

$$
\begin{aligned}
& \mathrm{X}=\sum \frac{\bar{X}}{\mathrm{~K}} \\
& \mathrm{X}=\sum 47,46 / 12 \\
& \mathrm{X}=3,955
\end{aligned}
$$


Tabel 4. Penilaian Pelanggan Pada Tingkat yang Diharapkan

\begin{tabular}{|c|c|c|c|c|c|c|c|c|c|c|c|c|c|c|}
\hline \multirow[b]{2}{*}{ No } & \multirow[b]{2}{*}{$\begin{array}{l}\text { Variabel Kualitas } \\
\text { Pelayanan }\end{array}$} & \multicolumn{5}{|c|}{ Tingkat Yang Dirasakan } & \multirow[b]{2}{*}{ Jml. } & \multicolumn{5}{|c|}{ Skor } & \multirow[b]{2}{*}{ Jml. } & \multirow{2}{*}{$\begin{array}{l}\text { Rata- } \\
\text { rata } \\
(\%)\end{array}$} \\
\hline & & SM & $\mathrm{M}$ & $\mathrm{CM}$ & $\begin{array}{l}K \\
M\end{array}$ & TM & & 5 & 4 & 3 & 2 & 1 & & \\
\hline \multicolumn{15}{|c|}{ Frekuensi Gangguan } \\
\hline 1 & $\begin{array}{l}\text { Kestabilan tegangan di } \\
\text { tempat anda }\end{array}$ & 100 & 0 & 0 & 0 & 0 & 100 & 500 & 0 & 0 & 0 & 0 & 500 & 5 \\
\hline 2 & $\begin{array}{l}\text { Kontinuitas listrik (tidak } \\
\text { pernah padam) }\end{array}$ & 100 & 0 & 0 & 0 & 0 & 100 & 500 & 0 & 0 & 0 & 0 & 500 & 5 \\
\hline 3 & $\begin{array}{l}\text { Lamanya padam dan } \\
\text { respon pemulihan }\end{array}$ & 95 & 5 & 0 & 0 & 0 & 100 & 475 & 20 & 0 & 0 & 0 & 495 & 4,95 \\
\hline \multicolumn{15}{|c|}{ Respon Pengaduan } \\
\hline 4 & $\begin{array}{l}\text { Kecepatan merespon } \\
\text { keluhan pelanggan } \\
\text { (kWh prabayar error, } \\
\text { muncul tulisan "periksa") }\end{array}$ & 99 & 1 & 0 & 0 & 0 & 100 & 495 & 4 & 0 & 0 & 0 & 499 & 4,99 \\
\hline 5 & $\begin{array}{l}\text { Kecepatan petugas } \\
\text { mengatasi keluhan } \\
\text { pelanggan }\end{array}$ & 95 & 5 & 0 & 0 & 0 & 100 & 475 & 20 & 0 & 0 & 0 & 495 & 4,95 \\
\hline 6 & $\begin{array}{l}\text { Keterbukaan informasi } \\
\text { perhitungan tagihan }\end{array}$ & 98 & 2 & 0 & 0 & 0 & 100 & 490 & 8 & 0 & 0 & 0 & 498 & 4,98 \\
\hline \multicolumn{15}{|c|}{ Pelayanan PB/PD/PS } \\
\hline 7 & $\begin{array}{l}\text { Kejelasan dan } \\
\text { kemudahan prosedur } \\
\text { PB/PD/PS }\end{array}$ & 81 & 16 & 3 & 0 & 0 & 100 & 405 & 64 & 9 & 0 & 0 & 478 & 4,78 \\
\hline 8 & $\begin{array}{l}\text { Kecepatan pelayanan } \\
\text { permohonan } \\
\text { PB/PD/PS }\end{array}$ & 91 & 6 & 3 & 0 & 0 & 100 & 455 & 24 & 9 & 0 & 0 & 488 & 4,88 \\
\hline \multicolumn{15}{|c|}{ Layanan Lainnya } \\
\hline 9 & $\begin{array}{l}\text { Kemudahan memahami } \\
\text { informasi di Web, call } \\
\text { centre, media cetak }\end{array}$ & 90 & 9 & 1 & 0 & 0 & 100 & 450 & 36 & 3 & 0 & 0 & 489 & 4,89 \\
\hline 10 & $\begin{array}{l}\text { Kemudahan } \\
\text { menghubungi call centre } \\
\text { PLN } 123\end{array}$ & 90 & 9 & 1 & 0 & 0 & 100 & 450 & 36 & 3 & 0 & 0 & 489 & 4,89 \\
\hline 11 & $\begin{array}{l}\text { Layanan gratis bongkar } \\
\text { pasang kWh prabayar } \\
\text { jika mengalami error }\end{array}$ & 90 & 10 & 0 & 0 & 0 & 100 & 450 & 40 & 0 & 0 & 0 & 490 & 4,90 \\
\hline 12 & $\begin{array}{l}\text { Kemudahan dalam } \\
\text { membeli voucher listrik } \\
\text { prabayar }\end{array}$ & 99 & 1 & 0 & 0 & 0 & 100 & 495 & 4 & 0 & 0 & 0 & 499 & 4,99 \\
\hline $\begin{array}{l}\text { pada } \\
\text { men } \\
\text { pers }\end{array}$ & $\begin{array}{l}\text { ari Tabel } 4 \text { terlihat } \\
\text { tingkat yang dih } \\
\text { ari total nilai rata-rat } \\
\text { naan } 5 \text { berikut: }\end{array}$ & $\begin{array}{l}\text { apk } \\
\text { me }\end{array}$ & ggu & $\begin{array}{l}\text { Intuk } \\
\text { akan }\end{array}$ & & & $\Sigma 59$ & $2 / 1$ & & & & & & \\
\hline
\end{tabular}




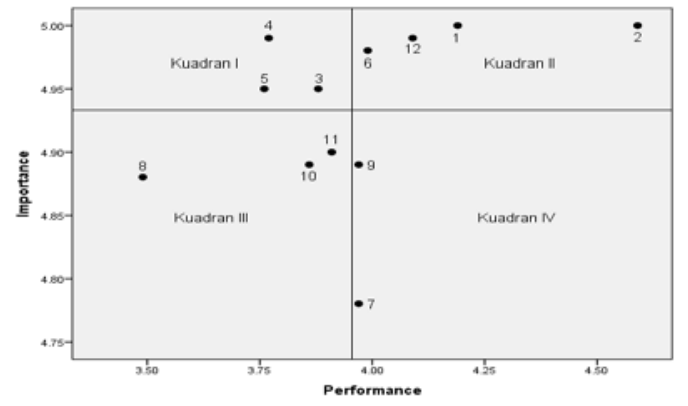

Gambar 2. Diagram Kartesius Analysis Importance Performance

.Pada Gambar 2 prioritas utama untuk dibenahi pada diagram kartesius Importance Performance Analysis adalah lamanya padam dan respon pemulihan, kecepatan merespon keluhan pelanggan (kWh prabayar error, muncul tulisan "periksa pada kWh prabayar", dan kecepatan petugas mengatasi keluhan pelanggan.

\subsection{Urutan Peringkat Item Pertanyan}

Tabel 5. Urutan Peringkat Tingkat Dirasakan Oleh Pelanggan

\begin{tabular}{|c|c|c|c|}
\hline No & $\begin{array}{l}\text { Item } \\
\text { Pertan } \\
\text { yaan } \\
\text { Ke- }\end{array}$ & Keterangan & $\begin{array}{l}\text { Nilai } \\
\text { rata- } \\
\text { rata } \\
(\%)\end{array}$ \\
\hline 1 & 2 & Kontinuitas listrik & 4,59 \\
\hline 2 & 1 & $\begin{array}{l}\text { Kestabilan tegangan di } \\
\text { tempat anda }\end{array}$ & 4,18 \\
\hline 3 & 12 & $\begin{array}{c}\text { Kemudahan dalam } \\
\text { membeli voucher listrik } \\
\text { prabayar }\end{array}$ & 4,09 \\
\hline 4 & 6 & $\begin{array}{l}\text { Keterbukaan informasi } \\
\text { perhitungan tagihan }\end{array}$ & 3,99 \\
\hline 5 & 9 & $\begin{array}{c}\text { Kemudahan memahami } \\
\text { informasi di Web, cetak, } \\
\text { elektronik }\end{array}$ & 3,97 \\
\hline 6 & 7 & $\begin{array}{l}\text { Kejelasan dan kemudahan } \\
\text { prosedure PB/PD/PS }\end{array}$ & 3,97 \\
\hline 7 & 11 & $\begin{array}{c}\text { Layanan gratis bongkar } \\
\text { pasang kWh prabayar jika } \\
\text { error }\end{array}$ & 3,91 \\
\hline 8 & 3 & $\begin{array}{l}\text { Lamanya padam dan } \\
\text { respon pemulihan }\end{array}$ & 3,88 \\
\hline 9 & 10 & $\begin{array}{l}\text { Kemudahan menghubungi } \\
\text { call centre PLN } 123\end{array}$ & 3,86 \\
\hline 10 & 4 & $\begin{array}{c}\text { Kecepatan merespon } \\
\text { keluhan pelanggan }\end{array}$ & 3,77 \\
\hline 11 & 5 & $\begin{array}{l}\text { Kecepatan petugas } \\
\text { mengatasi keluhan } \\
\text { pelanggan }\end{array}$ & 3,76 \\
\hline 12 & 8 & $\begin{array}{l}\text { Kecepatan pelayanan } \\
\text { permohonan PB/PD/PS }\end{array}$ & 3,49 \\
\hline
\end{tabular}

Berdasarkan urutan peringkat item yang memiliki nilai paling tinggi dan paling rendah adalah kontinuitas listrik 4,59\% dan kecepatan pelayanan permohonan PB/PD/PS 3,49\%.

\section{KESIMPULAN}

Simpulan dari hasil pengolahan data, semua item pertanyaan pada kuisioner dinyatakan valid yang ditunjukkan pada pengujian validitas menggunakan software SPSS. Prioritas utama untuk dibenahi pada diagram kartesius Analysis Importance Performance adalah lamanya padam dan respon pemulihan, kecepatan merespon keluhan pelanggan (kWh prabayar error, muncul tulisan "periksa pada kWh prabayar", dan kecepatan petugas mengatasi keluhan pelanggan. Berdasarkan urutan peringkat item yang memiliki nilai paling tinggi dan paling rendah adalah kontinuitas listrik 4,59\% dan kecepatan pelayanan permohonan PB/PD/PS 3,49\%.

\section{DAFTAR PUSTAKA}

[1] Atmawati dan Wahyuddin. 2007 : 2. Pemasaran Jasa dan Kuliatas Pelayaann. Bayu Media Publishing, Malang.

[2] Kotler, Philip, dan Garry Amstrong. 2005. Dasar-Dasar Pemasaran, Prenhallindo, Jakarta.

[3] Arikunto, Suharsimi. 2006. Prosedur Penelitian: Suatu Pendekatan Praktek Edisi Revisi. PT. Rineka Cipta. Jakarta.

[4] Widiyanto, Joko. 2010. SPSS for Windows untuk Analisis Data Statistik dan Penelitian. Surakarta : BP-FKIP UMS.

[5] Supranto, J. 1997. Pengukuran Tingkat Kepuasan Pelanggan Untuk Memasukkan Pangsa Pasar. Jakarta : PT Rineka Cipta.

[6] Widyaningrum, Riny. 2004. Analisis Kualitas Pelayanan Terhadap Kepuasan Pelanggan (studi Kasus di PDAM Tirta Pakuan Kota Bogor). Bogor: Institut Pertanian Bogor. 